\title{
Increased detection in Australia and Singapore of a novel influenza $A(H 1 N 1) 2009$ variant with reduced oseltamivir and zanamivir sensitivity due to a S247N neuraminidase mutation
}

\author{
A C Hurt (Aeron.Hurt@influenzacentre.org)1, R T Lee ${ }^{2}$, S K Leang ${ }^{1}$, L Cui ${ }^{3}$, Y M Deng ${ }^{1}$, S P Phuah³, N Caldwell ${ }^{1}$, K Freeman ${ }^{4}$, \\ N Komadina', D Smith', D Speers ${ }^{5}$, A Kelso ${ }^{1}$, R T Lin³, S Maurer-Stroh',3,6, I G Barr ${ }^{1}$ \\ 1. World Health Organization Collaborating Centre for Reference and Research on Influenza, North Melbourne, Victoria, Australia \\ 2. Bioinformatics Institute (BII), Agency for Science, Technology and Research (A*STAR), Singapore \\ 3. National Public Health Laboratory, Communicable Diseases Division Ministry of Health, Singapore \\ 4. Serology/Molecular Biology Department, Royal Darwin Hospital, Darwin, Australia \\ 5. PathWest Laboratory Medicine, Nedlands, Western Australia \\ 6. School of Biological Sciences (SBS), Nanyang Technological University (NTU), Singapore
}

Citation style for this article:

Hurt AC, Lee RT, Leang SK, Cui L, Deng YM, Phuah SP, Caldwell N, Freeman K, Komadina N, Smith D, Speers D, Kelso A, Lin RT, Maurer-Stroh S, Barr IG. Increased detection in Australia and Singapore of a novel influenza A(H1N1)2009 variant with reduced oseltamivir and zanamivir sensitivity due to a S247N neuraminidase mutation.

Euro Surveill. 2011;16(23):pii=19884. Available online: http://www.eurosurveillance.org/ViewArticle.aspx?Articleld=19884

A novel influenza $A\left(\mathrm{H}_{1} \mathrm{~N}_{1}\right) 2009$ variant with mildly reduced oseltamivir and zanamivir sensitivity has been detected in more than $10 \%$ of community specimens in Singapore and more than $30 \%$ of samples from northern Australia during the early months of 2011. The variant, which has also been detected in other regions of the Asia-Pacific, contains a $247 \mathrm{~N}$ neuraminidase mutation. When combined with the $\mathrm{H}_{275} \mathrm{Y}$ mutation, as detected in an oseltamivir-treated patient, the dual S247 N+H275Y mutant had extremely high oseltamivir resistance.

\section{Introduction}

The emergence and global spread in 2007/08 of an oseltamivir-resistant seasonal influenza $A\left(\mathrm{H}_{1} \mathrm{~N}_{1}\right)$ variant containing a histidine to tyrosine substitution $(\mathrm{H} 275 \mathrm{Y})$ in the neuraminidase (NA), demonstrated the potential for drug-resistant influenza viruses to arise and spread within the community in the absence of drug-selective pressure [1]. Since the start of the 2009 pandemic, the oseltamivir-resistant $\mathrm{H}_{2} 75 \mathrm{Y}$ variant has only been detected on rare occasions in pandemic influenza $A\left(\mathrm{H}_{1} \mathrm{~N}_{1}\right) 2009$ community specimens ( $\left.<1 \%\right)$, although recent reports have suggested that this frequency may be increasing [2]. Other NA mutations in influenza $A\left(\mathrm{H}_{1} \mathrm{~N}_{1}\right)_{2009}$ viruses have been reported to confer mildly reduced oseltamivir and/or zanamivir sensitivity, such as substitutions at the isoleucine residue at position 223 ( $\mathrm{N}_{1}$ numbering), but the detection of these mutants has been very rare and has occurred mostly in isolated cases of immunocompromised individuals under long-term NA inhibitor (NAI) treatment $[3,4]$. Here we report the identification and increased rate of detection in community samples of a novel influenza $A\left(\mathrm{H}_{1} \mathrm{~N}_{1}\right)_{2009}$ variant with reduced oseltamivir and zanamivir sensitivity. The variant contained a serine to asparagine mutation at residue $247\left(\mathrm{~S}_{247} \mathrm{~N}\right)$ of the NA, and has been detected in recent community specimens from Australia, Brunei and Singapore. Although the mutation has been described before in a small number of seasonal influenza $A\left(\mathrm{H}_{1} \mathrm{~N}_{1}\right)$ and highly pathogenic influenza $A\left(\mathrm{H}_{5} \mathrm{~N}_{1}\right)$ viruses with reduced $\mathrm{NAI}$ sensitivity $[5,6]$, it has not previously been reported in influenza $A\left(\mathrm{H}_{1} \mathrm{~N}_{1}\right)_{2} 009$ viruses, and has not occurred in any strains at the frequencies that are described here.

\section{Materials and methods}

Specimens and isolates from the Asia-Pacific region were submitted to the World Health Organization (WHO) Collaborating Centre for Reference and Research on Influenza, Melbourne, as part of the WHO Global Influenza Surveillance Network. Isolates cultured in Madin-Darby canine kidney (MDCK) cells were analysed for oseltamivir, zanamivir and peramivir sensitivity using a fluorescence-based neuraminidase inhibition assay [7]. Oseltamivir carboxylate, the active form of the ethyl ester prodrug oseltamivir phosphate, was kindly provided by Hoffmann-La Roche Ltd, Switzerland; zanamivir was kindly provided by GlaxoSmithKline, Australia; peramivir was kindly provided by BioCryst, United States. Isolates and specimens were sequenced using standard techniques at the WHO Collaborating Centre, Melbourne, except for Singaporean strains which were sequenced at the National Public Health Laboratory, Singapore. Haemagglutinin ( $\mathrm{HA})$ and NA sequences reported here have been deposited on GISAID (www.gisaid.org; accession numbers $\mathrm{EPI}_{319165}$ to EPI319183) or GenBank (accession numbers CYo91664 to CYo91724 and CYo63853 to CYo63854). Other HA and NA sequences were analysed from GISAID or Genbank sequence databases (see supplementary* for details: http://mendel.bii.a-star.edu.sg/ SEQUENCES/H1N1/S247N/Hurt_et_al_NA-S247N_suppl. 
pdf). A concatenated $\mathrm{HA}$ and NA nucleotide alignment was created with MAFFT (FFT-NS-2) (http://mafft.cbrc. jp/alignment/software/) and a maximum likelihood phylogenetic tree was generated with PhyML (http:// www.atgc-montpellier.fr/phyml/) using the HKY85 substitution model, 4 gamma-distributed categories (shape parameter 0.46 ) and the approximate likelihood ratio test. The trees were visualised and annotated in MEGA5 (http://www.megasoftware.net/).

The S247N and dual S247N+H275Y NA mutations were investigated further by site-directed mutagenesis and reverse genetics using the eight-plasmid system. Mutations were engineered into the NA of influenza A/ Auckland/1/2009( $\left.\mathrm{H}_{1} \mathrm{~N}_{1}\right)$ and transfected together with plasmids containing the seven remaining segments from the influenza A/Puerto Rico/8/34 strain, as described previously [8].

The mutations $\mathrm{S} 247 \mathrm{~N}$ and $\mathrm{H} 275 \mathrm{Y}$ were modelled into the influenza $\mathrm{A}\left(\mathrm{H}_{1} \mathrm{~N}_{1}\right) 2009$ neuraminidase crystal structure and the effects of the mutations on oseltamivir binding were visualised and examined using FoldX (http:// foldx.crg.es) and Yasara (http://www.yasara.org).

\section{Results}

From April 2009 to December 2010, over 2,900 influenza $A\left(H_{1} N_{1}\right) 2009$ influenza viruses from the Asia-Pacific region were analysed for NAI sensitivity with only 23 $\mathrm{H} 275 \mathrm{Y}$ oseltamivir-resistant viruses detected (0.8\%), and virtually all of the remaining strains being fully sensitive to both oseltamivir and zanamivir. However

\section{FIGURE 1}

Detection of influenza A(H1N1)2009 S247N variants since $2009^{* *}$

A

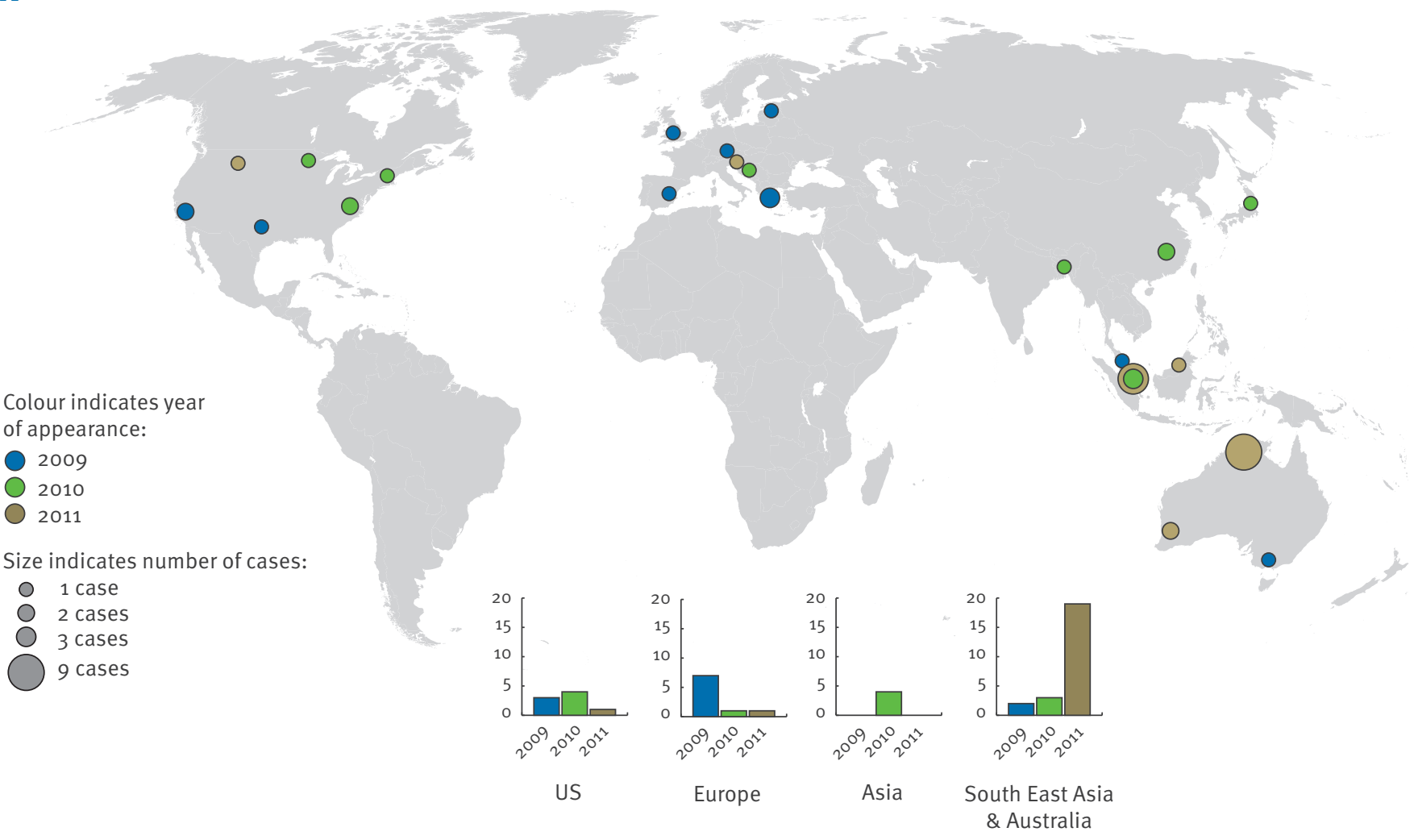

B

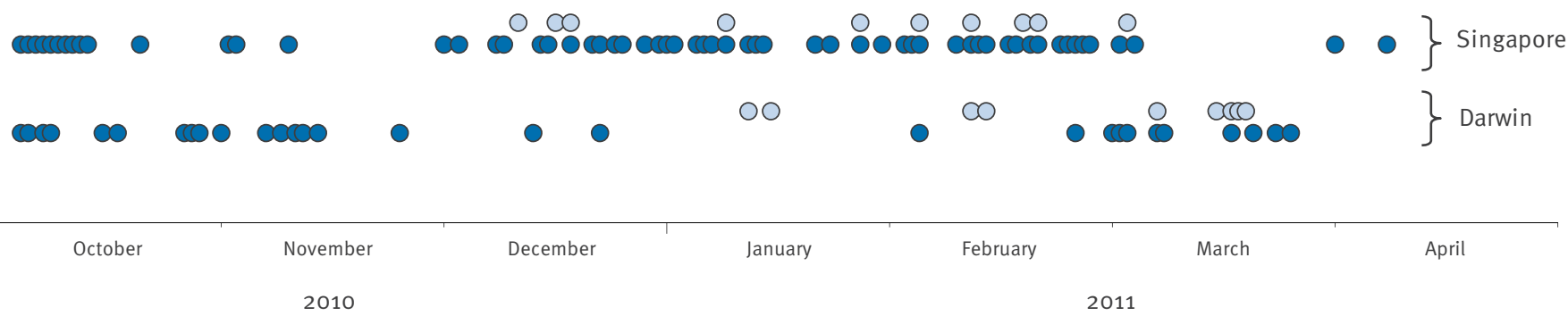

A. Year and frequency of detection of $\mathrm{S} 247 \mathrm{~N}$ mutants globally since $2009(n=49)$. Dots are overlaid on top of each other for Singapore.

B. Detection of S247N mutants in Darwin and Singapore between October 2010 and April $2011(n=19)$. S247N mutants are indicated by light blue circles and wildtype S247 viruses are indicated by dark blue circles. 
since December 2010, 22 influenza $A\left(\mathrm{H}_{1} \mathrm{~N}_{1}\right) 2009$ viruses containing a novel S247N NA mutation (S246N based on $\mathrm{N} 2$ numbering), have been detected in both clinical specimens and isolates from the Asia-Pacific region. The majority of the $5247 \mathrm{~N}$ variants detected since December $2010(n=19)$ have occurred in two clusters, one in the Darwin region in northern Australia and the other in Singapore (Figure 1A). The variant has also been detected in Western Australia and Brunei (in this study), and based on data from the public sequence databases has occurred, albeit rarely, in other locations such as the United States, Europe and Asia since 2009 (Figure 1A). During the first three months of 2011, 28 influenza $A\left(\mathrm{H}_{1} \mathrm{~N}_{1}\right) 2009$ strains were sampled from the Darwin region, of which nine contained the $\mathrm{S} 247 \mathrm{~N}$ mutation, while in Singapore 10 out of 80 viruses sampled since December 2010 had the S247N NA mutation (Figure 1B).

Of the 22 S247N variants detected, nine were cultured and in an NA inhibition assay showed a mean sixfold reduction in oseltamivir sensitivity, a three-fold reduction in zanamivir sensitivity, and no significant

\section{TABLE}

Neuraminidase inhibitor sensitivity of naturally occurring and recombinant S247N and S247N+H275Y influenza A(H1N1)2009 variants, December 2010-March 2011

\begin{tabular}{|c|c|c|c|c|c|c|c|c|}
\hline \multirow[b]{2}{*}{ Virus } & \multirow[b]{2}{*}{ Mutation } & \multirow[b]{2}{*}{$\begin{array}{l}\text { Specimen } \\
\text { date }\end{array}$} & \multicolumn{2}{|c|}{ Zanamivir } & \multicolumn{2}{|c|}{ Oseltamivir carboxylate } & \multicolumn{2}{|c|}{ Peramivir } \\
\hline & & & $\begin{array}{l}\text { Mean IC } \\
\pm \mathrm{SD}(\mathrm{nM})\end{array}$ & $\begin{array}{c}\text { x-fold } \\
\text { difference } \\
\text { vs } \\
\text { wildtype }\end{array}$ & $\begin{array}{l}\text { Mean IC } \\
\pm \mathrm{SD}(\mathrm{nM})\end{array}$ & $\begin{array}{c}\text { x-fold } \\
\text { difference } \\
\text { vs } \\
\text { wildtype }\end{array}$ & $\begin{array}{l}\text { Mean IC } \\
\pm \mathrm{SD}(\mathrm{nM})\end{array}$ & $\begin{array}{c}x \text {-fold } \\
\text { difference } \\
\text { vs } \\
\text { wildtype }\end{array}$ \\
\hline $\begin{array}{l}\text { Mean of sensitive } \\
\text { influenza } A\left(H_{1} N_{1}\right) \\
2009 \text { viruses } \\
(n=3,169)\end{array}$ & - & - & $0.28 \pm 0.15$ & - & $0.45 \pm 0.35$ & - & $0.20 \pm 0.10^{\mathrm{a}}$ & - \\
\hline $\begin{array}{l}\text { Mean of } \mathrm{S}_{247 \mathrm{~N}} \\
\text { influenza } \mathrm{A}\left(\mathrm{H}_{1} \mathrm{~N}_{1}\right) \\
2009 \text { viruses }^{\mathrm{b}} \\
(\mathrm{n}=9)\end{array}$ & S247N & - & $0.85 \pm 0.10$ & 3 & $2.68 \pm 0.61$ & 6 & $0.21 \pm 0.02$ & 1 \\
\hline \multicolumn{9}{|c|}{ Naturally occurring strains } \\
\hline $\begin{array}{l}\text { A/Singapore/ } \\
\text { GP4565/2010 }\end{array}$ & $\mathrm{S} 247 \mathrm{~N}$ & $\begin{array}{c}10 \mathrm{Dec} \\
2010\end{array}$ & $0.96 \pm 0.06$ & 3 & $3.21 \pm 0.50$ & 7 & $0.21 \pm 0.02$ & 1 \\
\hline $\begin{array}{l}\text { A/Singapore/ } \\
\text { GP4588/2010 }\end{array}$ & $\mathrm{S} 247 \mathrm{~N}$ & $\begin{array}{l}15 \mathrm{Dec} \\
2010\end{array}$ & $0.81 \pm 0.08$ & 3 & $3.02 \pm 0.54$ & 7 & $0.21 \pm 0.02$ & 1 \\
\hline A/Darwin/2/2001 & S247N & $\begin{array}{l}13 \mathrm{Jan} \\
2011\end{array}$ & $0.88 \pm 0.10$ & 3 & $3.20 \pm 0.47$ & 7 & $0.23 \pm 0.01$ & 1 \\
\hline A/Brunei/1/2011 & $\mathrm{S} 247 \mathrm{~N}$ & $\begin{array}{l}13 \text { Jan } \\
2011\end{array}$ & $0.86 \pm 0.08$ & 3 & $1.62 \pm 0.11$ & 4 & $0.26 \pm 0.03$ & 1 \\
\hline A/Darwin/10/2011 & S247N & $\begin{array}{l}9 \text { Feb } \\
2011\end{array}$ & $0.79 \pm 0.08$ & 3 & $2.41 \pm 0.47$ & 5 & $0.19 \pm 0.01$ & 1 \\
\hline A/Perth/30/2011 & S247N & $\begin{array}{l}1 \mathrm{Mar} \\
2011\end{array}$ & $0.80 \pm 0.01$ & 3 & $2.34 \pm 0.21$ & 5 & $0.22 \pm 0.01$ & 1 \\
\hline A/Perth/29/2011 ${ }^{c}$ & $\begin{array}{c}\mathrm{S} 247 \mathrm{~N}+ \\
\mathrm{H} 275^{\mathrm{Y}}\end{array}$ & $\begin{array}{l}8 \text { Mar } \\
2011\end{array}$ & $1.30 \pm 0.08$ & 5 & $2,646.81 \pm 293.55$ & 5,880 & $66.88 \pm 4.19$ & 334 \\
\hline A/Darwin/70/2011 & $\mathrm{S} 247 \mathrm{~N}$ & $\begin{array}{c}14 \text { Mar } \\
2011\end{array}$ & $1.04 \pm 0.10$ & 4 & $3.49 \pm 0.45$ & 8 & $0.21 \pm 0.01$ & 1 \\
\hline A/Darwin/74/2011 & $\mathrm{S} 247 \mathrm{~N}$ & $\begin{array}{l}16 \text { Mar } \\
2011\end{array}$ & $0.68 \pm 0.03$ & 2 & $2.15 \pm 0.23$ & 5 & $0.19 \pm 0.01$ & 1 \\
\hline A/Darwin/75/2011 & $\mathrm{S} 247 \mathrm{~N}$ & $\begin{array}{c}17 \text { Mar } \\
2011\end{array}$ & $0.82 \pm 0.04$ & 3 & $2.69 \pm 0.11$ & 6 & $0.21 \pm 0.02$ & 1 \\
\hline \multicolumn{9}{|c|}{ Recombinant strains $^{d}$} \\
\hline RG-wildtype & - & - & $0.24 \pm 0.05$ & - & $0.30 \pm 0.20$ & - & $0.09 \pm 0.01$ & - \\
\hline RG-S247N & $\mathrm{S} 247 \mathrm{~N}$ & - & $0.57 \pm 0.10$ & 2 & $0.96 \pm 0.48$ & 3 & $0.18 \pm 0.02$ & 2 \\
\hline $\begin{array}{l}\text { RG-S247N+ } \\
\mathrm{H}_{275} \mathrm{Y}\end{array}$ & $\begin{array}{l}\mathrm{S} 247 \mathrm{~N}+ \\
\mathrm{H} 275 \mathrm{Y}\end{array}$ & - & $1.25 \pm 0.17$ & 5 & $2,149 \cdot 96 \pm 309.02$ & 7,073 & $60.91 \pm 5.88$ & 704 \\
\hline $\mathrm{RG}-\mathrm{H} 275 \mathrm{Y}$ & $\mathrm{H} 275 \mathrm{Y}$ & - & $0.26 \pm 0.03$ & 1 & $195.02 \pm 21.05$ & 642 & $19.72 \pm 1.42$ & 228 \\
\hline
\end{tabular}

RG: reverse genetics; SD: standard deviation.

a Mean and standard deviation of peramivir IC ${ }_{50}$ values based on analysis of $n=273$ isolates.

${ }^{b}$ Mean does not include the dual $\mathrm{S} 247 \mathrm{~N}+\mathrm{H} 275 \mathrm{Y}$ mutant.

'Viruses were from the same patient before and after oseltamivir treatment (refer to the text for more details).

${ }^{d}$ Recombinant strains were derived using site-directed mutagenesis and reverse genetics. 


\section{FIGURE 2}

Phylogenetic trees of concatenated haemagglutinin and neuraminidase sequences from influenza A(H1N1)2009 S247N variants detected December 2010-March 2011

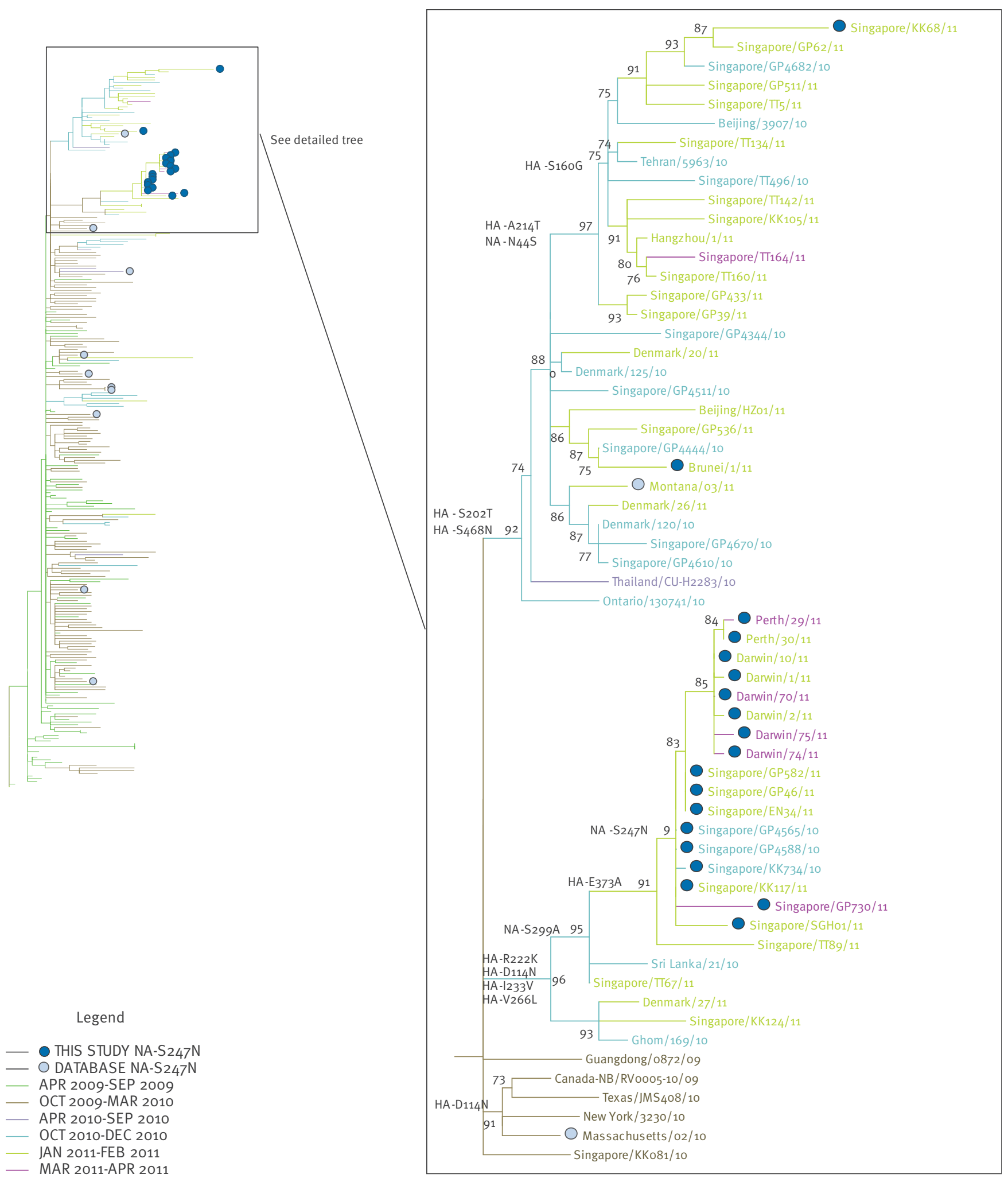

Dark blue dots: S247N variants identified in this study $(n=22)$; light blue dots: S247N variants previously reported on Genbank or GISAID sequence databases.

Branches and designations are coloured according to their sample collection date. The nucleotide sequences for these strains were concatenated such that a single sequence contains nucleotide sequences encoding both the haemagglutinin and neuraminidase proteins in order to increase the evolutionary signal for strain differences of these almost identical sequences. 


\section{FIGURE 3}

The structural effect of the S247N and S247N+H275Y mutations in the neuraminidase of influenza A(H1N1)

A

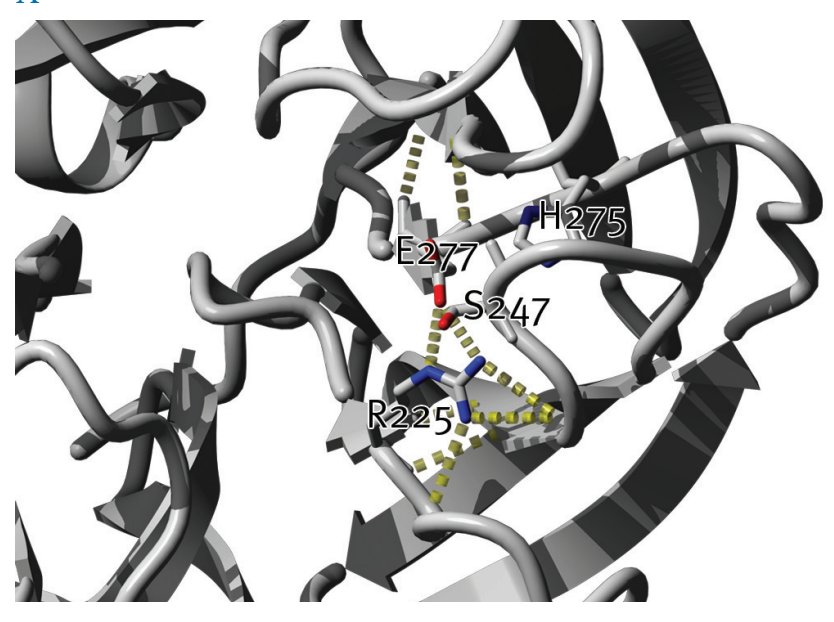

B

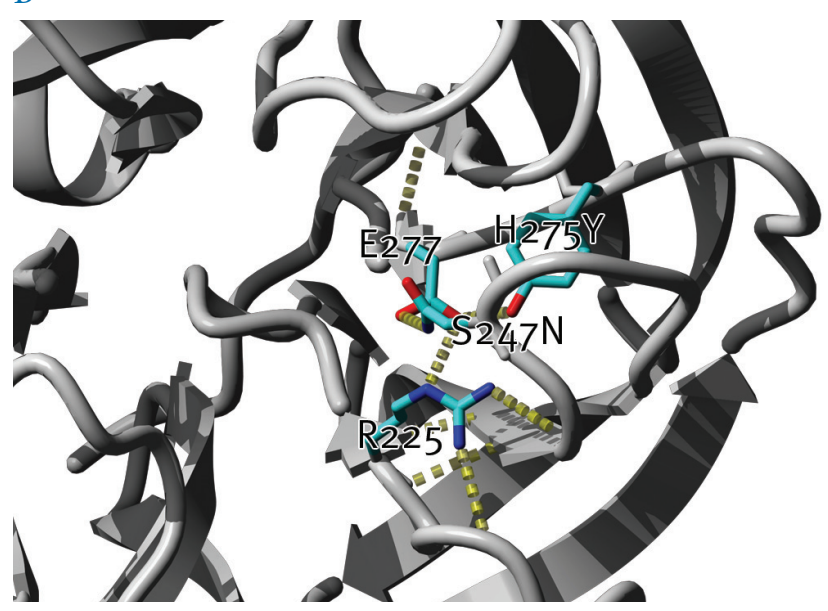

C
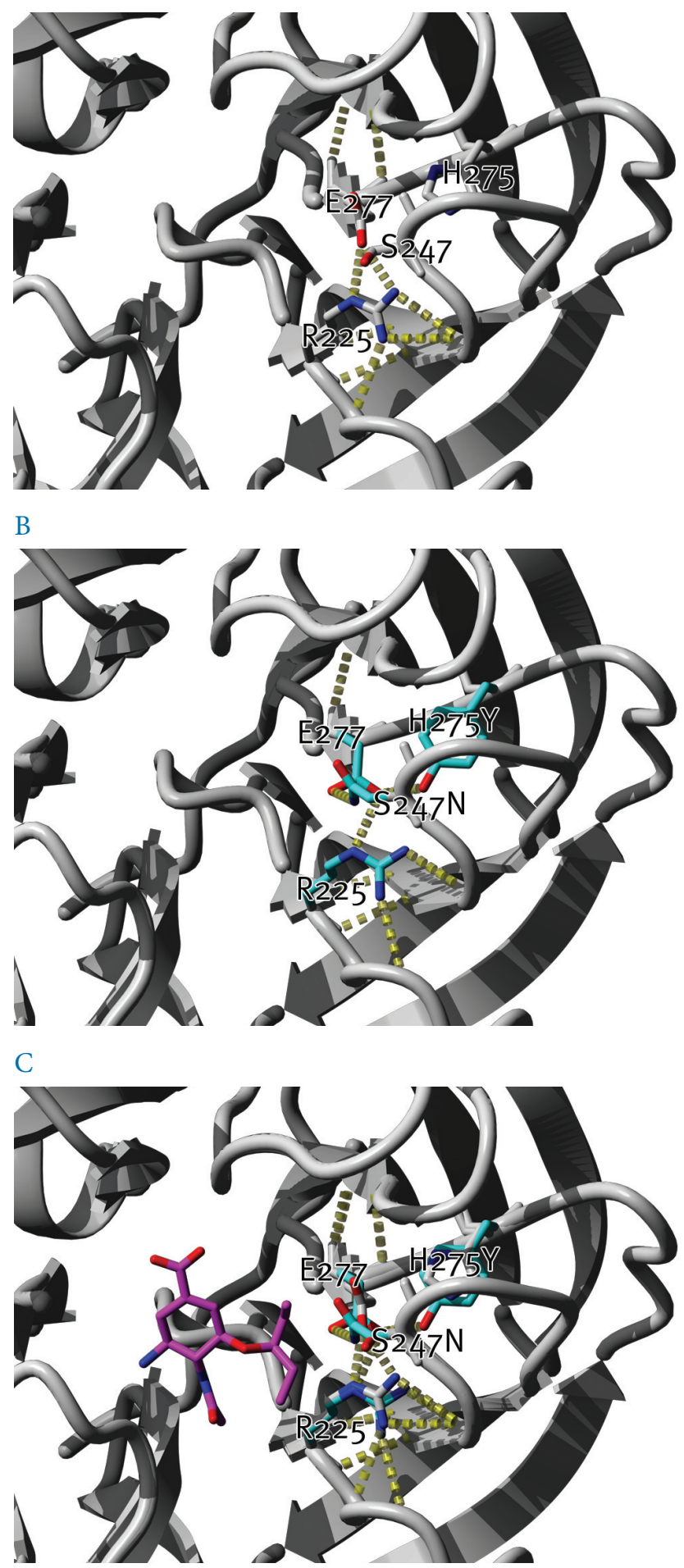

A. Wildtype.

B. Dual $\mathrm{S} 247 \mathrm{~N}+\mathrm{H} 275 \mathrm{Y}$ mutant.

C. The merged image shows the superimposition of the wildtype and the double mutant relative to bound oseltamivir (pink, from PDB:3clO ). The crystal structure of influenza $A\left(\mathrm{H}_{1} \mathrm{~N}_{1}\right) 2009$ neuraminidase (PDB:3nss, chain A) was used to model the double mutations $\mathrm{S} 247 \mathrm{~N}$ and $\mathrm{H}_{2} 25 \mathrm{Y}$ using Yasara.

Hydrogen bonds among the important residues are shown in yellow. Side chains of residues undergoing conformational changes upon the double mutation are shown in cyan. reduction in peramivir sensitivity compared to the mean IC ${ }_{50}$ (concentration required to inhibit $50 \%$ of NA activity) of sensitive influenza $\mathrm{A}\left(\mathrm{H}_{1} \mathrm{~N}_{1}\right) 2009$ viruses (Table).

In Perth, Western Australia, an immunocompromised patient was found on 1 March 2011 to be infected with an influenza virus that contained the S247N NA mutation (A/Perth/30/2011) (Table). Oseltamivir treatment was commenced two days after detecting the initial S247N variant (3 March). A sputum specimen collected five days later (8 March) contained an influenza virus with both the $\mathrm{S} 247 \mathrm{~N}$ and $\mathrm{H} 275 \mathrm{Y}$ NA mutations (A/Perth/29/2011) (Table). Despite commencement of intravenous zanamivir the patient died on 16 March from multiple organ failure. The isolate with the dual $\mathrm{S} 247 \mathrm{~N}$ and $\mathrm{H}_{275} \mathrm{Y}$ mutations had an oseltamivir IC nearly 6,000-fold higher than sensitive viruses and 10-fold higher than seen for influenza $A\left(\mathrm{H}_{1} \mathrm{~N}_{1}\right)_{2009}$ viruses with the $\mathrm{H}_{275} \mathrm{Y}$ mutation alone (Table). Clonal analysis of the virus population from the sputum specimen collected after oseltamivir treatment confirmed that both the $\mathrm{S}_{247} \mathrm{~N}$ and $\mathrm{H}_{275} \mathrm{Y}$ mutations occurred together in the NA. The effect of the S247N and dual $\mathrm{S} 247 \mathrm{~N}$ and $\mathrm{H} 275 \mathrm{Y}$ mutations on NAI sensitivity was confirmed by reverse genetics experiments (Table).

Sequence analysis of the $\mathrm{S} 247 \mathrm{~N}$ variants from the recent Darwin and Singapore clusters revealed that the majority belonged to the same genetic lineage (Figure 2). The two strains from the immunocompromised patient in Perth were also genetically similar to the Darwin and Singapore strains, but the virus from Brunei and one strain from Singapore were placed in a separate clade together with one other S247N strain from the United States (Figure 2).

Structural analyses indicate that the S247N mutation could change the hydrogen bonding network and side chain conformation of residue E277 (E276 by N2 numbering) reflecting similar but weaker alterations known from the $\mathrm{H}_{2} 75 \mathrm{Y}$ mutation. When adding $\mathrm{H}_{275} \mathrm{Y}$, E277 gets pushed further into the drug binding pocket which is believed to weaken oseltamivir binding (Figure 3).

\section{Discussion}

Previous studies have reported the effect of the S247N mutation on NAl sensitivity in $\mathrm{N}_{1}$ neuraminidases. The levels of oseltamivir and zanamivir sensitivity reported for the $\mathrm{S} 247 \mathrm{~N}$ mutation in a pre-pandemic seasonal influenza $A\left(\mathrm{H}_{1} \mathrm{~N}_{1}\right)$ virus were similar to those reported here for the mutation in influenza $A\left(\mathrm{H}_{1} \mathrm{~N}_{1}\right)_{2009}$ strains [5]. However a greater reduction in oseltamivir sensitivity was reported for a highly pathogenic influenza $\mathrm{A}\left(\mathrm{H}_{5} \mathrm{~N}_{1}\right)$ strain with a $\mathrm{S} 247 \mathrm{~N}$ mutation compared to the influenza $A\left(\mathrm{H}_{1} \mathrm{~N}_{1}\right)_{2009}$ strains reported here (24fold vs 6 -fold reduction compared to their respective wildtypes) [6]. The same study also reported on an 
influenza $\mathrm{A}\left(\mathrm{H}_{5} \mathrm{~N}_{1}\right)$ virus with the $\mathrm{S} 247 \mathrm{~N}$ and two additional mutations, $1223 \mathrm{~L}$ and $\mathrm{K}_{15} \mathrm{ON}$ (N1 numbering). This triple mutant virus had a greater reduction in oseltamivir sensitivity compared to the $5247 \mathrm{~N}$ mutation alone (77-fold vs 24 -fold reduction), further demonstrating that mutations at other key residues such as 1223 , in combination with $\mathrm{S} 247 \mathrm{~N}$, can cumulatively decrease NAI sensitivity. Given that a number of studies have recently reported 1223 mutations conferring $\mathrm{NAl}$ resistance in influenza $\mathrm{A}\left(\mathrm{H}_{1} \mathrm{~N}_{1}\right) 2009$ strains $[3,4,9,10]$, and that data from the United Kingdom show an increased frequency of $\mathrm{H}_{275} \mathrm{Y}$ mutants in community samples [2], the likelihood of mutation combinations $\mathrm{S} 247 \mathrm{~N}+1223 \mathrm{X}$ and $\mathrm{S} 247 \mathrm{~N}+\mathrm{H} 275 \mathrm{Y}$ is considerably increased if the S247N influenza $A\left(\mathrm{H}_{1} \mathrm{~N}_{1}\right) 2009$ variant continues to spread.

Pharmacokinetic data would suggest that the maximum drug levels achieved via the recommended dose easily exceed the observed $I_{50}$ values of the $S 247 \mathrm{~N}$ mutant [11], and therefore the variant is unlikely to be clinically resistant. However, it is noteworthy that recent clinical studies have demonstrated a reduced oseltamivir efficacy for normal influenza B viruses [12] which have IC ${ }_{50}$ values only 6 -fold higher than that of

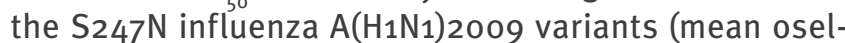
tamivir $I C_{50} \pm S D$ for influenza $B$ viruses from 2010 and 2011: $15.5 \mathrm{nM} \pm 11.3(n=557))$. Data from Singapore and Darwin demonstrate that the $5247 \mathrm{~N}$ variant is able to circulate widely and therefore does not appear to have compromised viral fitness or transmissibility. If the S247N variant spreads globally, the greatest concern is that other NA mutations which may have previously caused only mild reductions in NAI susceptibility (e.g. mutations at the 1223 residue) could instead cumulatively decrease NAI sensitivity to levels that may be clinically significant and affect treatment efficacy. Laboratories should consider screening currently circulating specimens and isolates for the S247N NA mutation to determine whether the variant is spreading into other regions.

*Note: Supplementary information made available by the authors on an independent website is not edited by Eurosurveillance, and Eurosurveillance is not responsible for the content.

**Erratum: The map in Figure 1 was misaligned with the dots. This was corrected on 10 June 2011

\section{Acknowledgements}

The authors wish to thank the various laboratories that submit specimens and isolates to the Melbourne WHO Collaborating Centre for Reference and Research on Influenza. The reverse genetics plasmid pHW2000 was kindly provided by Dr Richard Webby, St Jude Children's Research Hospital, Memphis, United States. The Melbourne WHO Collaborating Centre for Reference and Research on Influenza is supported by the Australian Government Department of Health and Ageing.

\section{References}

1. Meijer A, Lackenby A, Hungnes O, Lina B, van der Werf $\mathrm{S}$, Schweiger B, et al. Oseltamivir-resistant influenza virus $A\left(\mathrm{H}_{1} \mathrm{~N}_{1}\right)$, Europe, 2007-08 season. Emerg Infect Dis. 2009;15(4):552-60.

2. Lackenby A, Moran Gilad J, Pebody R, Miah S, Calatayud L, Bolotin S, et al. Continued emergence and changing epidemiology of oseltamivir-resistant influenza $A\left(\mathrm{H}_{1} \mathrm{~N}_{1}\right) 2009$ virus, United Kingdom, winter 2010/11. Euro Surveill. 2011;16(5):19784. Available from: http://www.eurosurveillance. org/ViewArticle.aspx?Articleld=19784

3. van der Vries E, Stelma FF, Boucher CA. Emergence of a multidrug-resistant pandemic influenza $A\left(\mathrm{H}_{1} \mathrm{~N}_{1}\right)$ virus. N Engl J Med. 2010;363(14):1381-2.

4. Nguyen HT, Fry AM, Loveless PA, Klimov AI, Gubareva LV. Recovery of a multidrug-resistant strain of pandemic influenza A 2009 ( $\left.\mathrm{H}_{1} \mathrm{~N}_{1}\right)$ virus carrying a dual $\mathrm{H}_{2} 75 \mathrm{Y} / \mathrm{I}_{22} 2 \mathrm{R}$ mutation from a child after prolonged treatment with oseltamivir. Clin Infect Dis. 2010;51(8):983-4.

5. Sheu TG, Deyde VM, Okomo-Adhiambo M, Garten RJ, Xu X, Bright RA, et al. Surveillance for neuraminidase inhibitor resistance among human influenza $A$ and $B$ viruses circulating worldwide from 2004 to 2008 . Antimicrob Agents Chemother. 2008;52(9):3284-92.

6. Boltz DA, Douangngeun B, Phommachanh P, Sinthasak S, Mondry $\mathrm{R}$, Obert $\mathrm{C}$, et al. Emergence of $\mathrm{H}_{5} \mathrm{~N}_{1}$ avian influenza viruses with reduced sensitivity to neuraminidase inhibitors and novel reassortants in Lao People's Democratic Republic. J Gen Virol. 2010;91(Pt 4):949-59.

7. Hurt AC, Barr IG, Hartel G, Hampson AW. Susceptibility of human influenza viruses from Australasia and South East Asia to the neuraminidase inhibitors zanamivir and oseltamivir. Antiviral Res. 2004;62(1):37-45.

8. Hurt AC, Holien JK, Barr IG. In vitro generation of neuraminidase inhibitor resistance in $\mathrm{A}\left(\mathrm{H}_{5} \mathrm{~N}_{1}\right)$ influenza viruses. Antimicrob Agents Chemother. 2009;53(10):4433-40.

9. Rousset D, Le Goff J, Abou-Jaoude G, Molina JM, Scemla $A$, Caro V, et al. Emergence of succesive mutations in the neuraminidase of the pandemic $\mathrm{H}_{1} \mathrm{~N}_{1}$ virus respectively associated with oseltamivir resistance and reduced susceptbility to both oseltamivir and zanamivir under treatment with neuraminidase inhibitors. Options for the Control of Influenza VII; 2010; Hong Kong. Abstract Book. P-198.

10. Santos L, Correia V, Giria M, Pedro S, Santos M, Silvestre $M$, et al. Genetic and antiviral drug susceptbility profiles of pandemic $A\left(\mathrm{H}_{1} \mathrm{~N}_{1}\right) v$ influenza virus circulating in Portugal. Options for the Control of Influenza VII; 2010; Hong Kong. Abstract Book.0-851.

11. He G, Massarella J, Ward P. Clinical pharmacokinetics of the prodrug oseltamivir and its active metabolite Ro 64-0802. Clin Pharmacokinet. 1999;37(6):471-84.

12. Sugaya N, Mitamura K, Yamazaki M, Tamura D, Ichikawa M, Kimura K, et al. Lower clinical effectiveness of oseltamivir against influenza $B$ contrasted with influenza $A$ infection in children. Clin Infect Dis. 2007;44(2):197-202. 